\title{
LOS ESTUDIOS HISPÁNICOS EN CHECOSLOVAQUIA
}

\author{
Zdenek Hampejs
}

Praga

El objetivo de este. artículo es informar sobre el estado y las perspectivas de los estudios hispánicos en Checoslovaquia. Hablaremos ante todo de los últimos quince años, es decir, de la época de post-guerra y dedicaremos nuestra atención tanto a los trabajos de lingüística iberorrománica, como a los de historia literaria que abarcan la esfera de España y los países americanos de habla española, de Portugal y Brasil.

En el pasado la actividad de los hispanistas era dispersa y se realizaba sólo gracias a la iniciativa individual. A ella se deben, p. ej., los 300 libros traducidos del español en el siglo XIX y en las primeras cuatro décadas del siglo $X X$. También en la lingüistica los pocos trabajos sobre el español que existen, deben su existencia sólo a una iniciativa personal.

Hoy los hispanistas no trabajan como individuos dispersos y desligados unos de otros, sino, preparan sus trabajos según un plan general, representando un equipo que se da cuenta de sus deberes ante el público que se interesa por el español y el portugués.

En la esfera de la lingüística españo!a, nuestros hispanistas han dedicado su atención tanto a trabajos científicos como a trabajos didácticos. De los primeros, que servirán de base para una gramática científica del español, en preparación, son dignos de mención los estudios, publicados en Casopis pro moderní filologii (=Revista de Filología Moderna) y en Philologica Pragensia, revistas editadas por la Academia Checoslovaca de Ciencias, en la revista Cizí jazyky ve skole (=Lenguas extranjeras en la escuela) y en las actas de las Universidades de Praga, Brno y Olomouc y en 
los cuales sus autores tratan p. ej. de los tiempos, del orden de las palabras, del problema ortográfico, etc. del español. Un im. portante trabajo científico. es Základy spaneslské mluvnice (=Fundamentos de la gramática española), 1958, de O. T i c h y. De gran importancia son también dos manuales para la enseñanza universitaria: Úvod do dejin spanelského jazyka (=Introducción a la historia de la lengua española), 1958, de J. D u b s k y y Nástin fonetiky jazyka spanelského (=Esbozo de fonética de la lengua española), 1957, de K. O h n e s o r g, así como varios manuales prácticos de español. Estos múltiples manuales sirven para la enseñanza del español en los cursos del Instituto de lenguas, de Praga, de las escuelas económicas de segundo grado, de los ministerios y empresas industriales y comerciales y en las Universidades.

Entre los estudios y monografías sobre la literatura española son de primordial importancia los trabajos de O. B e $\mid$ i c. Su Dejiny spanelské literatury (=Historia de la literatura española), t. 1, 1957, que abarca la época del auge del feudalismo, es interesante para cualquier historiador literario, ya que presenta una nueva "periodización" de la antigua literatura española y un nuevo método para el enfoque de este problema en escala general. Notable es también la monografía de Belic sobre Vicente Blasco Ibáñez, 1953, que analiza sus conceptos de la sociedad, su método artístico y la relación entre el escritor y la generación del 98. Los otros trabajos de Belic versan sobre el Poema del Mío Cid, sobre la novela picaresca, sobre Cervantes, sobre el realismo en la literatura española del siglo $X \mid X$, sobre Valle-Inclán y la literatura de la España de hoy, etc.

Otros hispanistas estudian la difusión de la literatura española en nuestro país y la poesía española moderna: hay que citar, sobre todo, el trabajo, recientemente acabado, de K. U h l i r sobre A. Machado y algunos problemas de la poesía española de los comienzos del siglo $X X$.

Sería injusto omitir obras de carácter didáctico, que son también de incontestable utilidad, p. ej., Dejiny spanelské literatury (=Historia de la literatura española), 1951, de J. O. F i s c h er, la crestomatía de Zd. H a m p e j s: Prehled dejin spanelské lite- 
ratury (=Esbozo de la historia de la literatura española), en dos tomos, 1957-1958, la antología de V. H v i z d a l a: Ukázky z moderni spanelské literatury (=Trozos escogidos de la literatura española moderna), 1957, etc.

Un poco menos intensa es la atención que los hispanistas checos dedican a la literatura iberoamericana. Con excepción de su breve historia, escrita por $\mathrm{Zd}$. $\mathrm{H}$ a $\mathrm{m} \mathrm{p}$ e j s y de un estudio de $K$. U h I i r sobre el héroe positivo en la novala latinoamerican de hoy, se han publicado solamente prefacios y postfacios (de K. Uhlír, Zd. Hampejs, O. Belic etc.) a las obras de la literatura latinoamericana, traducidas al checo. Es de esperar que en el futuro los trabajos que proyectan $K$. U h li r sobre la moderna novela argentina y $\mathrm{O}$. $\mathrm{B}$ e $\mathrm{I}$ i $\mathrm{c}$ sobre la literatura chilena, representarán una nueva etapa - etapa más fértil - en nuestros estudios de la literatura latinoamericana.

En cuanto a los estudios de la lengua portuguesa y las literaturas portuguesa y brasileña, tuvieron en el pasado un desarrollo aún menor que los estudios de la lengua y literatura españolas. Lo único realizado se debe al interés de algunas personas, p. ej., Jules C o r $n$ u, romanista suizo que residia en Praga, o J. C e c h I, maestro de portugués en la Universidad Carolina de Praga. Pero ni ellos ni otros que publicaron algo sobre la lengua y literatura portuguesas, fundaron sus estudios sistemáticos. Eso acontece sólo hoy.

Habiendo sido las literaturas portuguesa y brasileña casi desconocidas, fue necesario dar al público checo la posibilidad de leer las más importantes obras de ambas. Una vez publicadas las obras zumbres del tesoro literario luso-brasileño (p. ej., obras de Camões, Eça de Queiroz, de los neorealistas portugueses, de los clásicos brasileños, etc., traducidas, en su mayor parte, por el autor de este artículo), resulta hoy posible profundizar el estudio (hasta hoy limitado a prefacios y postfacios, a los ensayos publicados en revistas, etc.), en monografías científicas que serán una base para la historia de las letras portuguesa y brasileña.

Para la divulgación de la lengua portuguesa será muy útil el primer manual checo del portugués: Ucebnice portugalstiny (=Manual del portugués), 1960, de Zd. H a m pej s y J. H o I$b i k$. De los trabajos teóricos sobre esta lengua citemos los estu- 
dios de $\mathrm{Zd}$. H a m p e j s sobre el infinitivo conjugado y la ortografía, que formarán parte de una gramática científica del portugués, en curso de preparación. Un extenso capítulo, dedicado al portugués por $\mathrm{Zd}$. $\mathrm{H}$ a $\mathrm{m} \mathrm{p} \in \mathrm{j} \mathrm{s}$, en el manual: Úvod do románskej jazykovedy (=Introducción a la linguística románica), 1959, de J. Skult é t y y Zd. Hampejs, será base del estudio teórico de esta lengua en las Universidades, donde la enseñanza del portugués se ha limitado hasta hoy a cursos prácticos. En los círculos, cada vez crecientes, de los interesados por el portugués, se espera con impaciencia la publicación del primer diccionario portugués-checo y checo-portugués, que ha sido elaborado por el autor.

En cuanto al catalán (con excepción de un estudio sobre la lengua catalana, de $\mathrm{Zd}$. $\mathrm{H}$ a $\mathrm{m}$ p e j s, incluido en la obra, ya citada, de J. Skultéty y Zd. Hampejs, Úvod do románskej jazykovedy), todavía no existen estudios lingüísticos ni literarios. Pero es de esperar que, en un próximo futuro, los hispanistas reanudarán una antigua tradición catalanista en nuestro país y dedicarán más atención tanto a la lengua catalana que tuvo, entre nosotros, un gran cultor en la persona de R. J. S I a b y, como a la literatura catalana, traducida y estudiada, en el pasado, por tres importantes personalidades de la cultura nacional, J. V r ch l i cky, S. B o u sk a y $A$. P ikhardt.

Lo que acabamos de decir, se refiere a Bohemia y Moravia, regiones del país, en las cuales se habla checo y donde hay tres ciudades universitarias. En la región oriental del país, Eslovaquia, cuyo centro universitario es Bratislava, los estudios hispánicos están solo en sus comienzos. Pero gracias a la actividad del traductor $V$. O l e $r$ ín y el público eslovaco conoce ahora, en su idioma nacional, varios escritores de la Península lbérica y la América Latina. Oleríny es también autor de una monografía sobre Cervantes (Cervantes, 1955) y de varios artículos sobre las más destacadas figuras de la cultura hispánica (J. R. Jiménez, Eça de Queiroz, etc.)

Esperamos que este artículo, por más breve que sea, muestre como nuestros hispanistas se esfuerzan por desarrollar en todos los aspectos los estudios hispánicos en Checoslovaquia. 